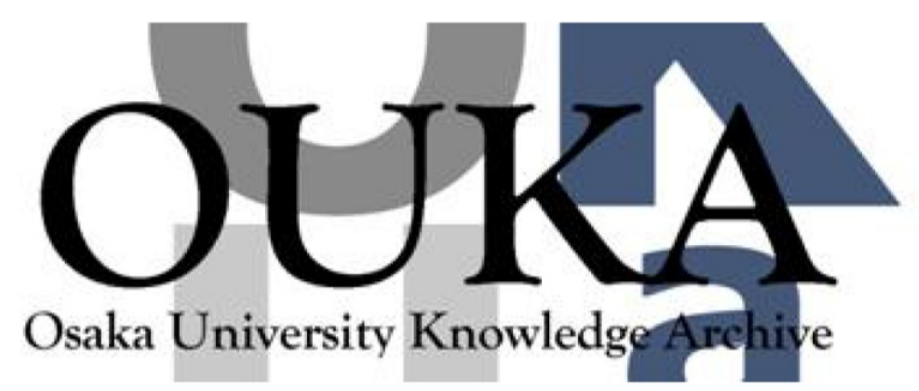

\begin{tabular}{|c|l|}
\hline Title & $\begin{array}{l}\text { Structural and functional analyses of the Arg- } \\
\text { Gly-Asp sequence introduced into human Lysozyme }\end{array}$ \\
\hline Author(s) & $\begin{array}{l}\text { Yamada, Takao; Matsushima, Masaaki; Inaka, Koji } \\
\text { et al. }\end{array}$ \\
\hline Citation & $\begin{array}{l}\text { Journal of Biological Chemistry. 268(14) } \\
\text { p. 10588-p. 10592 }\end{array}$ \\
\hline Issue Date & $1993-05$ \\
\hline oaire:version VoR \\
\hline URL & https://hdl. handle.net/11094/71440 \\
\hline rights & \\
\hline Note & \\
\hline
\end{tabular}

Osaka University Knowledge Archive : OUKA

https://ir. Library. osaka-u. ac. jp/

Osaka University 


\title{
Structural and Functional Analyses of the Arg-Gly-Asp Sequence Introduced into Human Lysozyme*
}

(Received for publication, December 14, 1992, and in revised form, January 20, 1993)

\author{
Takao Yamada, Masaaki Matsushima, Koji Inakał, Tadayasu Ohkubo, Atsuko Uyeda,

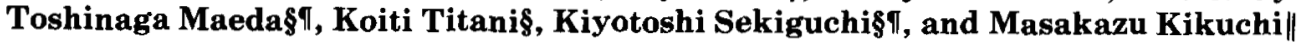 \\ From the Protein Engineering Research Institute, 6-2-3, Furuedai, Suita, Osaka 565, Japan, the §Institute for Comprehensive \\ Medical Science, Fujita Health University School of Medicine, Toyoake, Aichi 470-11, Japan, and the $\uparrow$ Research Institute, Osaka \\ Medical Center for Maternal and Child Health, Izumi, Osaka 590-02, Japan
}

To determine the functional conformation of the ArgGly-Asp (RGD) sequence, we have constructed mutant proteins by inserting 4-12 amino acid residues from the RGD region of human fibronectin between $\mathrm{Val}^{74}$ and $A_{s n}{ }^{75}$ of human lysozyme. RGDS-, GRGDSP-, TGRGDSPA-, VTGRGDSPAS-, and AVTGRGDSPASS-introduced mutant lysozymes were expressed in yeast, purified, and designated as RGD4, -6, -8, -10, and -12 , respectively. Using baby hamster kidney cells, RGD8, RGD10, and RGD12 were shown to possess high cell adhesion activity nearly equal to $10 \%$ of human vitronectin activity. RGD4 and RGD6 exhibited somewhat lower cell adhesion activity. The activities of these mutant proteins were inhibited by the addition of either GRGDSP peptide or polyclonal antibody against vitronectin receptor, as was the case for the vitronectin activity. The results suggest that the cell adhesion signals are transduced to cells through the interaction with the vitronectin receptor.

The three-dimensional structures of RGD4 and RGD8 were determined at $1.8-\AA$ resolution by $x$-ray crystallography. A model of the inserted region in RGD4 could be built in the electron density map, but the positions of the preceding residues, $\mathrm{Ala}^{73}-\mathrm{Val}^{74}$, were uncertain. The inserted region in RGD8 did not demonstrate continuous electron densities. The results suggest that these RGD sequence-containing regions are highly flexible and that such flexibility could allow the conformation of the RGD regions to be induced to fit into the binding pocket of the integrin receptor.

Cell adhesion is one of the most essential cellular functions for organisms, via which important signals in various biological processes such as cell metabolism, differentiation, and proliferation are transduced to cells from extracellular matrices or from other cells. In 1984, Pierschbacher and Ruoslahti (1) reported thàt fibronectin, a typical cell adhesive protein, contains an Arg-Gly-Asp (RGD) ${ }^{1}$ sequence as a cell recogni-

* The costs of publication of this article were defrayed in part by the payment of page charges. This article must therefore be hereby marked "advertisement" in accordance with 18 U.S.C. Section 1734 solely to indicate this fact.

† Present address: Research Laboratory of Resources Utilization, Tokyo Inst. of Technology, Nagatsuta, Midori-ku, Yokohama, Kanagawa 227, Japan.

If To whom correspondence should be addressed. Tel: 81-6-872 8213; Fax: 81-6-872-8210.

${ }^{1}$ The abbreviations used are: RGD, Arg-Gly-Asp; BHK, baby hamster kidney; DQF-COSY, double quantum filtered correlated spectroscopy; NOE, nuclear Overhauser enhancement; NOESY, NOE correlated spectroscopy. tion site. Since then, the functional RGD sequence has also been identified in other cell adhesive proteins present in extracellular matrices and body fluids. These proteins include vitronectin (2), laminin (3), collagens (4), fibrinogen (5), von Willebrand factor (6), and so on. In addition, cell surface receptor molecules for these proteins have been recently identified to be mutually homologous and termed integrins $(7,8)$.

Although a significant number of proteins have been found to contain the RGD sequence, only a limited number of them possess cell adhesion activity. This phenomenon could be explained by the idea that only the RGD sequence with an appropriate conformation can interact with the receptor molecules (9). The functional conformation of the RGD sequence remains to be solved, because the large molecular size of naturally occurring cell adhesive proteins, such as fibronectin, precludes the determination of their three-dimensional structures. Using methods for predicting secondary structure, Pierschbacher and Ruoslahti (1) have reported that the RGD region might reside within a $\beta$-turn, which forms a hydrophilic loop at the surface of the fibronectin molecule. Based on NMR spectroscopic studies, Reed et al. (10) have suggested that GRGDSP, one of the cell adhesive peptides, possesses unusual secondary structure with two $\beta$-bends. However, it is doubtful that such a structure would mimic a truly functional form of the RGD sequence. The reason for this is that peptides are flexible in nature and that the RGD-containing peptides should be coupled to a carrier protein for the measurement of cell adhesion activity (1).

To determine the functional conformation of the RGD sequence, we have tried introducing an RGD-containing sequence into a protein with a well defined structure, human lysozyme. Here we report the selection of mutant lysozymes with cell adhesion activity, and the examination of their structures by $\mathrm{x}$-ray crystallographic and two-dimensional NMR analyses. The functional conformation of the RGD sequence is discussed.

\section{EXPERIMENTAL PROCEDURES}

Materials-Restriction enzymes and T4 ligase were purchased from New England Biolabs (Beverly, MA) or Takara Shuzo (Kyoto, Japan). Micrococcus lysodeikticus cells were from Sigma. Human fibronectin was obtained from GIBCO, and human vitronectin was from Wako Pure Chemicals (Osaka, Japan). GRGDSP peptide was from Iwaki Glass (Tokyo, Japan). Rabbit antisera to human fibronectin receptor or to human vitronectin receptor were purchased from Telios (San Diego, CA).

Vector Constructions-Oligonucleotides were chemically synthesized using an automated DNA synthesizer (Model 380B, Applied Biosystems). The double-stranded DNA encoding RGDS or TGRGDSPA, for example, was obtained by annealing 5 '- $\overline{A G A G G T}$ GATTCT-3' and 5'-AGAATCACCTCT-3' or 5'-ACAGGTAGAGGTGATTCTCCTGCT-3' and 5'-AGCAGGAGAATCACCTCTA- 
CCTGT-3'. M13mp19XhLZM was ligated with the RGDS- or TGRGDSPA-coding gene after digesting with HincII, because the plasmid possesses a HincII restriction site between codons corresponding to $\mathrm{Val}^{74}$ and $\mathrm{Asn}^{75}$ of human lysozyme (11). The sequence of the mutant gene thus obtained was confirmed by dideoxy sequencing. The genes encoding the signal sequence and mutated human lysozyme were combined with an XhoI-Smal large fragment from pERI8602 (11) to construct the various expression plasmids.

Expression and Purification of Mutant Human Lysozymes-Mutant human lysozymes were expressed in yeast as described previously (12). Secreted mutant lysozymes were purified essentially as described (13). High performance liquid chromatography was performed using a cation exchange column (Asahipak ES-502C, Asahikasei Co. Ltd., Japan) and a hydroxyapatite column (TAPS-020810, Tonen K. K., Japan). The purified preparations thus obtained were judged to be homogeneous on SDS-polyacrylamide gel electrophoresis.

Measurement of Activity-Lytic activity was measured using $M$. lysodeikticus cells as a substrate (13). Protein was determined by measuring the weight in the freeze-dried form of each mutant lysozyme.

Cell adhesion activity was determined using BHK cells as described previously (14) except that 96-well enzyme immunoassay/radioimmunoassay plates (Costar Corp., Cambridge, MA) were used instead of 24-well bacteriological plates. The amount of protein adsorbed onto each plate was estimated by subtracting the unadsorbed amount from the added amount of lysozyme in the assay. The unadsorbed amount was determined based on the lytic activity remaining in the sample solution after binding to the plate. The results indicated that the adsorption efficiency was in the range of $60-80 \%$ at the concentrations shown in Fig. 1, regardless of native and mutant human lysozymes.

$X$-ray Crystallography-Crystals of RGD4 were grown from a solution containing $20 \mathrm{mg} / \mathrm{ml}$ protein, $2.5 \mathrm{M} \mathrm{NaCl}$ as a precipitant, and $30 \mathrm{~mm}$ sodium phosphate buffer, at $\mathrm{pH} 6.0$, in a chamber controlled at $13.0^{\circ} \mathrm{C}$. Crystals of RGD8 were grown under the same conditions except that $3.0 \mathrm{M} \mathrm{NaCl}$ was used as a precipitant. The data collection and structure refinements were carried out by the same methods as reported previously (15).

NMR Spectroscopy-Two-dimensional NMR spectra of RGD4 as well as native lysozyme were measured at pH 6.0 and 20,30 , and $40^{\circ} \mathrm{C}$, with a Bruker AM-600 spectrometer at $600 \mathrm{MHz}$ as described previously (16). In the RGD4 spectra, chemical shifts of the signals from the regions other than the inserted region were close to those in the spectra of the native form. The cross-peaks in the RGD4 spectra were identified by the standard procedure of sequential assignment, based on comparison with the spectra of native lysozyme (16).

\section{RESULTS}

We obtained a series of mutant human lysozymes, designated as RGD4, RGD6, RGD8, RGD10, and RGD12. They contain the fibronectin-derived RGD sequences, RGDS, GRGDSP, TGRGDSPA, VTGRGDSPAS, or AVTGRGDS$\mathrm{PASS}$, respectively, between $\mathrm{Val}^{74}$ and $\mathrm{Asn}^{75}$ of the lysozyme molecule. This introduction site was selected as convenient

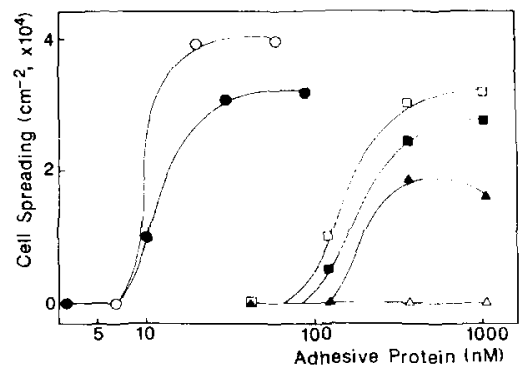

Fig. 1. Quantitative cell spreading assay on the substrates coated with each mutant lysozyme. The plastic substrates were coated with different concentrations of fibronectin $(O)$, vitronectin

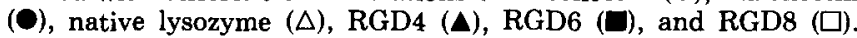
BHK cells were incubated on the substrates for $60 \mathrm{~min}$ in a $\mathrm{CO}_{2}$ incubator. The extent of cell spreading was expressed as the number of cells adhered to the unit surface area $\left(\mathrm{cm}^{2}\right)$. The concentration of fibronectin is expressed as that of the fibronectin monomer. for us in that M13mp19XhLZM possesses a restriction site between codons corresponding to $\mathrm{Val}^{74}$ and $\mathrm{Asn}^{75}(11)$ and in that the introduction site is present in a long loop exposed outside the lysozyme molecule (15). The productivity of these proteins in our yeast expression system was estimated by measuring lytic activity in the culture supernatant of each yeast transformant. As shown in Table I, mutant lysozymes as well as native lysozyme were secreted with high efficiency in the following order: RGD6 > RGD4 > native > RGD8 > RGD10 > RGD12. The low productivity of mutant lysozymes containing the long extra sequence, such as RGD10 and RGD12, could be due to problems in the folding pathway of these protein molecules. Table I also shows lytic activity of these mutant lysozymes, using $M$. lysodeikticus as a substrate. Their activities were nearly the same as that of the native form, indicating the insertion between $\mathrm{Val}^{74}$ and $\mathrm{Asn}^{75}$ had no effects on the active cleft of human lysozyme. The insertion site is distant from the active cleft of the lysozyme molecule (15), and this would allow the successful folding of these mutants with full lytic activity.

The measurement of cell adhesion activity was carried out using BHK cells (see Fig. $2 A$ ). The sample containing $20 \mathrm{nM}$ human fibronectin caused maximal activity, and it became inactive when diluted 3 -fold (Fig. 1). In the case of human vitronectin, the maximal level of activity was achieved at the concentration of $30 \mathrm{nM}$, and some residual activity was detectable after the 3-fold dilution (Fig. 1). The difference in these two assay curves is supposed to result from the specific response modes of two cell adhesive receptors, fibronectin receptor (integrin $\alpha_{5} \beta_{1}$ ) and vitronectin receptor (integrin $\left.\alpha_{\mathrm{v}} \beta_{3}\right)$, in BHK cells. Cell adhesion activity of RGD4, -6 , and -8 increased in parallel to the length of their introduced sequences (Fig. 1). RGD8 possesses quite high activity, which is nearly equal to $10 \%$ of vitronectin activity. Pierschbacher and Ruoslahti (1) reported previously that VTGRGDSPA(C), an RGD-containing peptide derived from human fibronectin, could achieve $50 \%$ maximal adhesion of normal rat kidney cells at the concentration of $2.5 \mu \mathrm{M}$. RGD8 might be severalfold more active than the RGD-containing peptide, although we cannot make a clear comparison because of the different assay conditions. RGD10 and -12 also showed cell adhesion activity comparable with that of RGD8 (data not shown).

We next attempted to determine whether these mutant lysozymes exhibit the cell adhesion activity via the interaction with fibronectin receptor or with vitronectin receptor present in BHK cells. The GRGDSP peptide has much higher affinity to vitronectin receptor than to fibronectin receptor (17), so that it completely inhibited the vitronectin activity at the concentration of $20 \mu \mathrm{M}$, while more than half of the fibronectin activity could be detected even in the presence of $2 \mathrm{mM}$ peptide (Fig. $2 B$ ). In the case of our mutant lysozymes, the inhibitory effect of the peptide was observed in a similar fashion to that seen with vitronectin (Fig. $2 B$ ). In addition, rabbit antiserum to vitronectin receptor neutralized the cell

TABLE I

Production and relative lytic activity of each mutant lysozyme

\begin{tabular}{lcc}
\hline & Productivity & $\begin{array}{c}\text { Relative lytic } \\
\text { activity }\end{array}$ \\
\hline Native & $m g / l$ liter & $\%$ \\
RGD4 & 5.3 & 100 \\
RGD6 & 6.3 & 109 \\
RGD8 & 7.1 & 94 \\
RGD10 & 3.8 & 95 \\
RGD12 & 2.9 & 83 \\
\hline
\end{tabular}

${ }^{a}$ Based on lytic activity in the culture supernatant. 
A

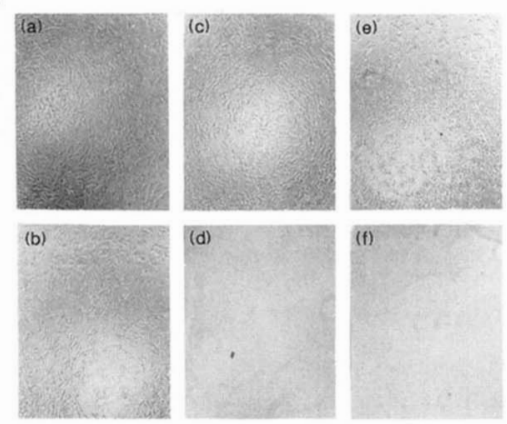

B

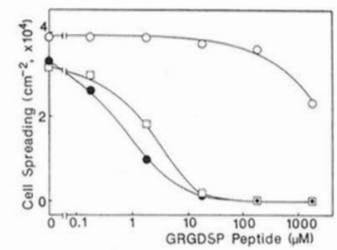

FIG. 2. Inhibitory effect of GRGDSP peptide on cell adhesion activity. $A$, photomicrographs of BHK cells adhered to the substrates coated with $20 \mathrm{nM}$ fibronectin ( $a$ and $b$ ), $30 \mathrm{nM}$ vitronectin $(c$ and $d)$, and 360 nM RGD8 ( $e$ and $f$ ). Cells were allowed to adhere to the substrates in the presence $(b, d, f)$ or absence $(a, c, e)$ of 200 $\mu \mathrm{M}$ GRGDSP peptide. $B$, dose-dependent inhibition of cell adhesion by GRGDSP peptide. The substrates were coated with $20 \mathrm{nM}$ fibronectin (O), $30 \mathrm{~nm}$ vitronectin $(\bullet)$, and $360 \mathrm{~nm}$ RGD8 ( $\square$ ). BHK cells were incubated on the substrates for $60 \mathrm{~min}$ in the presence of different concentrations of GRGDSP peptide. The cell adhesion activities of RGD4, $-6,-10$, and -12 were inhibited by the peptide in a similar manner to the RGD8 activity (data not shown).

adhesion activities of mutant lysozymes as well as vitronectin, and antiserum to fibronectin receptor neutralized only the fibronectin activity (data not shown). These experimental results demonstrate that the cell adhesion signals of mutant lysozymes are transduced to cells by the binding to the vitronectin receptor.

To reveal whether the inserted RGD region assumes a particular conformation in the protein structure, the threedimensional structures of RGD4 and RGD8 were examined crystallographically. Both mutant lysozymes were successfully crystallized using $\mathrm{NaCl}$ as a precipitant, and their x-ray diffraction data were collected. These crystals were isomorphous to that of the native protein, and their structures were solved by the molecular replacement method at 1.8 - $\AA$ resolution. The crystal data and the refinement parameters are summarized in Table II. A model of the inserted Arg-GlyAsp-Ser region in the RGD4 molecule could be built in its electron density map, but the positions of the preceding residues, $\mathrm{Ala}^{73}-\mathrm{Val}^{74}$, were uncertain (Fig. $3 B$ ). In the electron density map of RGD8, continuous electron densities for the inserted Thr-Gly-Arg-Gly-Asp-Ser-Pro region were not found, although the carboxyl-terminal Ala residue of the inserted region was clearly determined (Fig. $3 C$ ). In both cases, each of the inserted regions showed high B-factors (30$50 \AA^{2}$ ) as compared with those (less than $20 \AA^{2}$ ) in other regions of these mutant lysozymes. Therefore, it seems likely that these RGD sequence-containing regions are highly flexible in the protein structure.

We also measured the DQF-COSY and NOESY spectra of RGD4 to examine the structure in solution. The analyses of these spectra indicated that the RGD region failed to assume a specific secondary structure (Fig. $4 a$ ). In addition, the shortrange NOEs in the RGD region were shown to become very
TABLE II

Crystal structure analysis of each mutant lysozyme

\begin{tabular}{|c|c|c|c|}
\hline & Native & RGD4 & RGD8 \\
\hline Space group & $\mathrm{P} 2_{1} 2_{1} 2_{1}$ & $\mathrm{P} 2_{1} 2_{1} 2_{1}$ & $\mathrm{P} 2_{1} 2_{1} 2_{1}$ \\
\hline \multicolumn{4}{|l|}{ Cell constants $(\AA)$} \\
\hline a & 56.50 & 56.61 & 56.79 \\
\hline b & 60.89 & 60.85 & 60.97 \\
\hline $\mathrm{c}$ & 33.83 & 33.86 & 33.66 \\
\hline Resolution $(\AA)$ & 1.80 & 1.80 & 1.80 \\
\hline$R_{\text {merge }}^{a}$ & 0.050 & 0.038 & 0.056 \\
\hline No. of independent reflections & 10,109 & 10,744 & 10,586 \\
\hline No. of atoms & 1,121 & 1,142 & 1,243 \\
\hline$R$ factor ${ }^{b}$ & 0.164 & 0.146 & 0.152 \\
\hline \multicolumn{4}{|l|}{ r.m.s. deviation ${ }^{c}$} \\
\hline Bond distance $(\AA)$ & 0.016 & 0.015 & 0.014 \\
\hline Angle distance $(\AA)$ & 0.041 & 0.039 & 0.037 \\
\hline
\end{tabular}

${ }^{a} R_{\text {merge }}=\Sigma|I-\langle I\rangle| / \Sigma|\langle I\rangle|$.

${ }^{b} R$ factor $=\Sigma|| F_{\mathrm{o}}|-| F_{\mathrm{c}}|| / \Sigma\left|F_{\mathrm{o}}\right|$.

${ }^{c}$ Root mean square deviation from ideality.

weak at a high temperature $\left(40^{\circ} \mathrm{C}\right)$, as compared with those in other regions of the RGD4 molecule (Fig. 4). The result could be due to a signal broadening and demonstrates that the $R G D$ region is conformationally flexible.

\section{DISCUSSION}

To gain information on the functional conformation of a cell adhesive RGD signal, we introduced an RGD-containing sequence into human lysozyme whose structure could be determined easily by x-ray crystallography (15). In addition to the mutant proteins described here, we tried to construct three lysozyme variants by means of site-directed mutagenesis, namely 21RGD4 with RGDS in place of RGIS-(21-24), 101RGD4 with RGDS in place of RDPQ-(101-104), and 119RGD4 with $\overline{\text { RGDV }}$ in place of RDV-(119-121). These introduction sites were selected based on the following viewpoints. First, they possess a sequence easily substituted with the RGD sequence. Second, they are exposed outside the lysozyme molecule, allowing access to the integrin receptors. Third, they are expected to have little effect on lytic activity, which would enable us to determine the structure of the mutant lysozyme more easily. The mutant proteins, 101RGD4 and 119RGD4, were successfully secreted in our yeast expression system, while 21RGD4 failed to be folded correctly (data not shown). In the cell adhesion assay, moreover, 101RGD4 was inactive, and 119RGD4 possessed quite low activity, corresponding to less than $10 \%$ of RGD4 activity (data not shown).

A series of mutant lysozymes, RGD4, -6, -8, -10, and -12 , has a sequence from the fibronectin RGD region between $\mathrm{Val}^{74}$ and $\mathrm{Asn}^{75}$ of human lysozyme. The inhibitory experiments with GRGDSP peptide or antibodies to integrin receptors in our cell adhesion assay have shown that the cell adhesion signals in these mutant proteins are transduced to cells not by the interaction with fibronectin receptor (integrin $\alpha_{5} \beta_{1}$ ) but by the interaction with vitronectin receptor (integrin $\alpha_{\mathrm{v}} \beta_{3}$ ). In the case of the fibronectin-fibronectin receptor interaction, the presence of a second site besides the RGD region in the fibronectin molecule has been demonstrated (18), although it remains to be determined whether it also directly binds to the receptor or whether it supports the binding of the RGD region to the receptor. It is reasonable that like the GRGDSP peptide, the mutant lysozymes without the second site should show a high affinity for vitronectin receptor rather than for fibronectin receptor.

RGD8 possessed a high level of adhesion activity with BHK cells, which corresponds to one-tenth that of the natural ligand, vitronectin. No higher activity than that of RGD8 was 

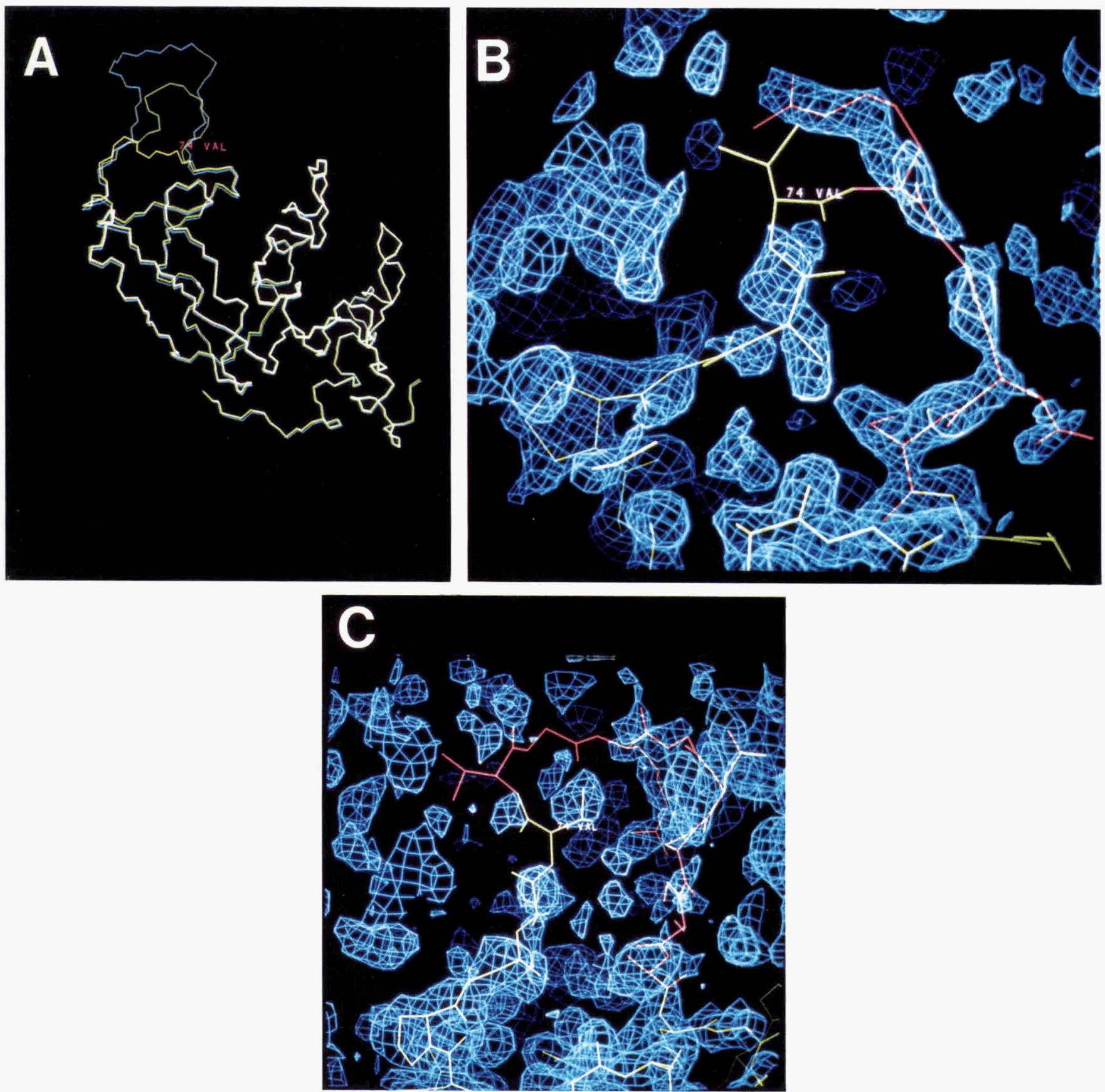

FIG. 3. Crystal structure of each mutant lysozyme. A, the backbone models of native lysozyme (yellow line), RGD4 (green line), and RGD8 (blue line). Val ${ }^{74}$ in the native form is labeled. The models were well superimposed except for the regions around the inserted residues. $B$, the $\left(2 F_{0}-F_{\mathrm{c}}\right)$ electron density map in the RGD region of RGD4. The atomic parameters of the 5 residues, $\mathrm{Gly}^{72}$ - $\mathrm{Ala}^{73}-\mathrm{Val}^{74}$-Arg-Gly, were eliminated in the phase calculations. The skeleton structure of the inserted region is shown in red. Val ${ }^{74}$ in $R G D 4$ is labeled. $C$, the $\left(2 F_{\circ}-\right.$ $F_{\mathrm{c}}$ ) electron density map in the RGD region of RGD8. The atomic parameters of the 10 residues, $\mathrm{Ala}^{73}$-Val ${ }^{74}-\mathrm{Thr}-\mathrm{Gly}$-Arg-Gly-Asp-Ser-ProAla, were eliminated in the phase calculations. The skeleton structure of the inserted region is shown in red. Val ${ }^{74}$ in RGD8 is labeled. In $B$ and $C$, the electron densities at the upper left and right sides belong to those of the neighboring protein molecules in the crystals.

observed in RGD10 and -12 . These results suggest that the introduced 8 amino acid residues are enough to form an active RGD conformation to some extent. The man-made proteins with a much higher level of cell adhesion activity, if any, would require quite a long $\mathrm{RGD}$-containing sequence derived from fibronectin or vitronectin.

Structural analyses of RGD4 and RGD8 have demonstrated that the region containing the RGD sequence is highly flexible in the protein molecule. Recently, Adler et al. (19) and Saudek et al. (20) have independently suggested on NMR spectro- scopic studies that the RGD-containing active site of disintegrin from snake venom is located at the apex of a mobile loop. This is a similar example to our mutant lysozyme, in which the RGD sequence is introduced in a long loop consisting of residues of $\mathrm{Cys}^{65}$ to $\mathrm{Cys}^{81}$ in the lysozyme molecule (15). In fact, as shown in Fig. $3 A$, the RGD regions of both mutants are present on a flexible loop extended from the protein surface, which would result in the expression of a high level of cell adhesion activity. It is known that disintegrins have a higher affinity to platelet GPIIb-IIIa, a member of the integrin 


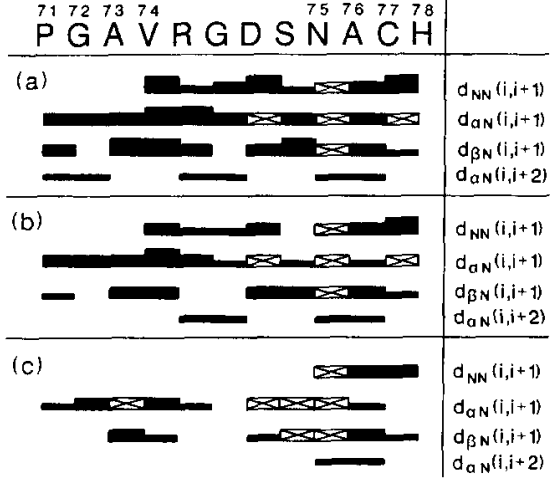

FIG. 4. Summary of short range NOEs in the RGD region of RGD4. The NOESY spectra were measured at $\mathrm{pH} 6.0$ and $20^{\circ} \mathrm{C}$ $(a), 30^{\circ} \mathrm{C}(b)$, and $40^{\circ} \mathrm{C}(\mathrm{c})$. The sequential NOEs are classified as strong, medium, and weak, as indicated by the thickness of the line. The symbol $\otimes$ is used for cross-peaks that are obscured by overlaps or are too close to the water line; therefore, the existence of these peaks cannot be verified. The numbers above the letter for a residue correspond to the residue numbers in the native form of human lysozyme.

family (integrin $\alpha_{\mathrm{In}} \beta_{3}$ ), than the native ligand, fibrinogen. Therefore, in the case of the natural cell adhesive proteins such as vitronectin, fibronectin, and fibrinogen, the functional RGD-containing regions might also be flexible. Quite recently, Leahy et al. (21) have expressed a fibronectin-type III domain from tenascin in Escherichia coli, solved the crystal structure by multiwavelength anomalous diffraction analysis of the selenomethionyl protein, and suggested that the RGD region is located in an extended type II' $\beta$-hairpin loop. In addition, Main et al. (22) have expressed the 10th type III module from human fibronectin using a yeast secretion system, determined the solution structure by NMR techniques, and demonstrated that the RGD region is solvent-exposed and lies on a conformationally mobile loop. Such flexibility in a loop structure could allow the conformation of the RGD region to be induced to fit into the binding pocket of the integrin receptor, as described in the antigen-antibody recognition (23) or in the cyclosporin A-cyclophilin interaction (24). Of course, we cannot completely rule out the possibility that the RGD regions in the intact molecules of the natural ligands have rigid and specific conformations by themselves. It would be essential for the clear understanding of the functional conformation of the RGD sequence to elucidate the structure of the RGDcontaining ligand-integrin receptor complex.

In the present investigation, we have managed to determine the conformation of the RGD region in cell adhesive lysozyme, RGD4, in spite of its flexibility. It is well known that cell-cell and cell-substrate interactions play important roles during various physiological phenomena such as tissue remodeling, platelet aggregation, and tumor metastasis. The information described here may be helpful in designing a primitive drug to modulate these functions.

Acknowledgments-We thank Drs. T. Miyazawa and M. Ikehara for encouragement and discussion throughout this work.

\section{REFERENCES}

1. Pierschbacher, M. D., and Ruoslahti, E. (1984) Nature 309, 30-33

. Suzuki S Oldberg A Hayman E. G Pierschbacher M D and Ruos lahti, E. (1985) $E M B O$ J. 4, 2519-2524

3. Sasaki, M., Kleinman, H. K., Huber, H., Deutzmann, R., and Yamada, Y. (1988) J. Biol. Chem. 263, 16536-16544

4. Bernard, M. P., Myers, J. C., Chu, M.-L., Ramirez, F., Eikenberry, E. F. and Prockop, D. J. (1983) Biochemistry 22, 1139-1145

5. Watt, K. W. K., Cottrell, B. A., Strong, D. D., and Doolittle, R. F. (1979) Biochemistry 18, 5410-5416

6. Titani, K., Kumar, S., Takio, K., Ericsson, L. H., Wade, R. D., Ashida, K. Walsh, K. A., Chopek, M. W., Sadler, J. E., and Fujikawa, K. (1986) Biochemistry $25,3171-3184$

7. Hynes, R. O. (1987) Cell 48, 549-554

8. Hemler, M. E. (1991) in Receptors for Extracellular Matrix (McDonald, J. A., and Mecham, R. P., eds) pp. 255-300, Academic Press, San Diego

9. Ruoslahti, E., and Pierschbacher, M. D. (1987) Science 238, 491-497

10. Reed, J., Hull, W. E., Lieth, C.-W., Kübler, D., Suhai, S., and Kinzel, V. (1988) Eur. J. Biochem. 178, 141-154

11. Taniyama, Y., Yamamoto, Y., Nakao, M., Kikuchi, M., and Ikehara, M. (1988) Biochem. Biophys. Res. Commun. 152, 962-967

12. Yoshimura, K., Toibana, A., Kikuchi, K., Kobayashi, M., Hayakawa, T. Nakahama, K., Kikuchi, M., and Ikehara, M. (1987) Biochem. Biophys. Nakahama, K., Kikuchi, M.,
Res. Commun. 145, 712-718

13. Taniyama, Y., Yamamoto, Y., Kuroki, R., and Kikuchi, M. (1990) J. Biol Chem. 265, 7570-7575

14. Maeda, T., Oyama, R., Ichihara-Tanaka, K., Kimizuka, F., Kato, I., Titani, K., and Sekiguchi, K. (1989) J. Biol. Chem. 264, 15165-15168

15. Inaka, K., Taniyama, Y., Kikuchi, M., Morikawa, K., and Matsushima, M (1991) J. Biol. Chem. 266, 12599-12603

16. Ohkubo, T., Taniyama, Y., and Kikuchi, M. (1991) J. Biochem. (Tokyo) $110,1022-1029$

17. Pierschbacher, M. D., and Ruoslahti, E. (1987) J. Biol. Chem. 262, 1729417298

18. Obara, M., Kang, M. S., and Yamada, K. M. (1988) Cell 53, 649-657

19. Adler, M., Lazarus, R. A., Dennis, M. S., and Wagner, G. (1991) Science $253,445-448$.

20. Saudek, V., Atkinson, R. A., and Pelton, J. T. (1991) Biochemistry 30, 7369-7372

21. Leahy, D. J., Hendrickson, W. A., Aukhil, I., and Erickson, H. P. (1992) Science 258, 987-991

22. Main, A. L., Harvey, T. S., Baron, M., Boyd, J., and Campbell, I. D. (1992) Cell 71, 671-678

23. Rini, J. M., Schulze-Gahmen, U., and Wilson, I. A. (1992) Science 255. 959-965

24. Kallen, J., Spitzfaden, C., Zurini, M. G. M., Wider, G., Widmer, H. Wüthrich, K., and Walkinshaw, M. D. (1991) Nature 353, 276-279 